\title{
Pentetic acid (DPTA) Cu(II) monolayer deposited on gold electrode-The base of biosensors for electrochemical screening of kinase JAK2 and potential inhibitor interactions
}

\author{
Justyn Wojtasik ${ }^{\mathrm{a}}$, Marcin Mielecki ${ }^{\mathrm{b}}$, Katarzyna Kurzątkowska ${ }^{\mathrm{a}}$, Krystyna Grzelak ${ }^{\mathrm{b}}$, Peter Verwilst $^{\mathrm{c}}$, Wim \\ Dehaen $^{\mathrm{c}}$, Jerzy Radecki ${ }^{\mathrm{a}}$, Hanna Radecka, ${ }^{\mathrm{a}}$, \\ ${ }^{a}$ Institute of Animal Reproduction and Food Research of the Polish Academy of Sciences, Tuwima 10 \\ Street, 10-748 Olsztyn, Poland \\ ${ }^{b}$ Institute of Biochemistry and Biophysics of the Polish Academy of Sciences, Pawińskiego 5A Street, \\ 02-106 Warsaw, Poland \\ ${ }^{c}$ KU Leuven, Chemistry Department, Celestijnenlaan 200F, B-3001 Leuven, Belgium
}

* tel.: +48 89523 4636, fax: +48 89524 0124, e-mail address: h.radecka@ pan.olsztyn.pl

\begin{abstract}
Here, the new biosensor destined for screening of interactions between kinase JAK2 and compounds which may act as inhibitors was presented. The $\mathrm{Cu}(\mathrm{II})$ complex of pentetic acid thiol ligand was applied for immobilization of kinase JAK2 on the gold electrode surface through his-tagged chemistry. The base of the biosensor response was the change of the electrochemical properties of the $\mathrm{Cu}(\mathrm{II})$ redox centres upon formation of the kinase JAK2-potential inhibitor complex. The increasing inhibitor concentration caused the decrease of reduction/oxidation $\mathrm{Cu}$ (II) current observed with Osteryoung square wave voltammetry. The biosensor usability was checked using known inhibitors, berberines-isoquinolone alkaloids, as well as caffeic acid — a control compound which has no affinity to kinase JAK2. The possible parameters suitable for estimation of the strength of the interactions between kinase JAK2 covalently attached to the $\mathrm{Cu}$ (II) complex of pentetic acid thiol ligand deposited on the gold electrode surface and potential inhibitors present in the solution were presented.
\end{abstract}

Keywords: pentetic acid thiol ligand, $\mathrm{Cu}(\mathrm{II})$ redox-active monolayer, His-tagged kinase JAK2 immobilization, kinase JAK2-potential inhibitor interactions, electrochemical biosensor 


\section{Introduction}

Janus kinases (JAKs), discovered in the early 1990s, are important non-receptor protein tyrosine kinases (PTKs). In mammals, the JAK family comprises four members: JAK1, JAK2, JAK3 and TYK2, which are crucial for cytokine, growth factor and interferon signaling pathways.

The JAK autophosphorylation induces a conformational change within itself, enabling it to transduce the intracellular signal by further phosphorylating and activating transcription factors called STATs (signal transducer and activator of transcription) [1-3].

Disorders of signaling pathways JAK/STAT may cause activity increase of STAT proteins observed in a number of autoimmune and cancer diseases [4,5]. Therefore, there is a great interest in searching for new kinase JAK inhibitors, which might be applied in molecular therapy.

The most commonly used tools to perform kinase activity screening are radioisotope methods [6], phosphor-specific antibodies [7,8], surface plasmon resonance [9-11], fluorescence resonance energy transfer-based systems $[12,13]$ and mass spectrometry $[14,15]$. The main drawbacks of these techniques are high cost, consumption of large amount of precious biological materials and long time of analysis. One of possible alternative strategy is the use of biosensors. They demand only very small amounts of analyzing materials, which decrease the cost of study. The growing interest of biosensor developments is well documented in numerous articles [16-19]. The electrochemical approaches destined for detection of protein phosphorylation and to assay the kinase activity have been developed by $\mathrm{Li}$ and co-workers. In general, their analytical strategy is based on substrate - product - electroactive markers electrostatic interactions. The enzyme-linked electrochemical strategy based on biotin labelled anti-phosphoserine and Au-nanoparticles loaded with HRP modified streptavidin have been successfully applied for study kinase inhibition behaviour of ellagic acid [20]. The very sensitive detection of protein phosphorylation was achieved by $\mathrm{Zr}^{+4}$ linkage between the phosphorylated peptide and DNA probe. The electrostatic interactions between long DNA strand and $\left[\mathrm{Ru}\left(\mathrm{NH}_{3}\right)_{6}\right]^{3+}$ strongly amplified the signal [21]. The charged difference of substrate peptide monolayer deposited on the electrode before and after phosphorylation recorded in the presence of positively charged redox marker is a base of switchable "on-off" electrochemical biosensors for screening kinase activity as well as its inhibition [22]. Polyethylene glycol (PEG) was suitable material for kinase protein entrapping. In this case, the interactions between kinase protein entrapped on PEG modified electrode and cAMP present in the solution was observed in the presence of negatively charged redox marker $\mathrm{Fe}(\mathrm{CN})_{6}^{-3 / 4}$ [23].

Here, proposed the new biosensor incorporated covalently attached on the electrode surface kinase JAK2 destined for exploring its interaction with potential inhibitors.

One of crucial parameter for biosensor fabrication is proper proteins immobilization on the solid surface of electrodes assuring their biological activity. The use of His-tag chemistry might secure this demand [24-26]. The most popular system for oriented immobilization of histidine-tagged proteins are complexes of transition metal ions $\left(\mathrm{Cu}^{2+}, \mathrm{Ni}^{2+}, \mathrm{Zn}^{2+}, \mathrm{Co}^{2+}\right)$ with ethylenediamine tetraacetic acid (EDTA), nitrilotriacetic acid (NTA) or iminodiacetic acid (IDA) [27-36].

The pentetic acid (diethylene triamine pentaacetic acid-abbreviation DTPA), polyamino carboxylic acid consisting of a diethylenetriamine backbone with five carboxymethyl groups, having high affinity for metal cations might be an alternative ligand. The formation constants for its complexes are about 100 greater than those for EDTA [37]. DPTA binds copper(II) in a hexadentate manner utilizing the three amine centres and three of the five carboxylates [38]. Molecular model computations based on CSChem-3D MOPAC, as well as spectral and thermogravimetric methods concerning homodinuclear complexes of transition metal cations with dianionic ligand $\left[\mathrm{H}_{3} \mathrm{DTPA}\right]^{-2}$ showed a hexacoordinate distorted octahedral environment around the metal ion [39]. The authors proved the presence of six coordinated water molecules, which might be replaced by other ligands. Cyclic voltammetry performed for $\left[\mathrm{Cu}_{2}\left(\mathrm{H}_{3} \mathrm{DTPA}\right)\left(\mathrm{H}_{2} \mathrm{O}\right)_{6}\right] \mathrm{Cl}_{2}{ }^{2+}$ present in the solution showed a quasi 
reversible $\mathrm{Cu} \mathrm{II} / \mathrm{I}$ redox couple at the potential $+0.04 \mathrm{~V}$ and $-0.11 \mathrm{~V}$, which is very suitable for sensor applications.

Therefore, in the study presented a $\mathrm{Cu}$ (II) complex with DPTA was applied for immobilization of kinase JAK2 on the gold electrode surface through his-tagged chemistry. The DPTA-Cu(II) complex formed on the surface of gold electrodes plays the double role: immobilization as well as transducer sites.

The biosensor proposed was used for electrochemical screening of interactions between JAK2 and known kinase inhibitors, as well as berberines, which are isoquinolone alkaloids. Control measurements with caffeic acid, which has no affinity to kinase JAK2 were also performed.

\section{Materials and methods}

\subsection{Chemicals and reagents}

Pentetic acid (DPTA) thiol ligand, palmatine and 13-benzylpalmatine were synthetized at the Chemistry Department of KU Leuven, Belgium. Trisma hydrochloride, glycerol, copper (II) acetate, Nacetylcysteamine (NAC), potassium chloride, sodium chloride, chloroform, sodium perchlorate, commercial inhibitors: tyrphostin AG-490 - (2E)-N-Benzyl-2-cyano-3-(3,4-dihydroxyphenyl)acrylamide and caffeic acid (3,4-dihydroxycinnamic acid), DDM were purchased from Sigma-Aldrich (Poznań, Poland). Other commercial inhibitors: Tasocitinib, K252a, Fasudil (1-(5-isoquinolinesulfonyl)homopiperazine), Erlotinib (N-(3-ethylenephenyl)-6,7-bis(2-methoxy-ethoxy)quinazolin-4-amine) were purchased from LC Laboratories (Canada). Potassium hydroxide, sodium hydroxide, sulfuric acid, sodium sulfate, cesium chloride, methanol and ethanol were purchased from POCH (Gliwice, Poland). Thesit was purchased from Fluka (Sigma-Aldrich, Poznań, Poland) and CHAPS, Tween-20 were purchased from BioShop (Lab Empire, Rzeszów, Poland). High purity water, resistivity $18.2 \mathrm{M} \Omega \mathrm{cm}$ (Millipore) was used for all experiments.

\subsection{Janus kinase 2 (rGST-His $\sigma_{6}$ JAK2) preparation}

The kinase domain of JAK2 (JH1) was expressed in baculovirus expression system Bac-to-Bac in HF insect cells (Invitrogen). The protein coding sequence was cloned into the plasmid pFastBac HT(Invitrogen) in frame with glutathione S-transferase (GST), S- and hexahistidine-tag (His ${ }_{6}$ ) sequences. Subsequently, the whole cassette was introduced into the bacmid DNA. Transfection of Sf21 cells with recombinant bacmid, propagation of recombinant baculovirus in Sf21 cells and infection of HF cells were all carried out according to the Invitrogen's manual.

The recombinant JAK2 (rGST-His $\left.{ }_{6}-\mathrm{JAK} 2\right)$ was purified from HF insect cells lysates applying two-step affinity chromatography on Ni-NTA-agarose and glutathione-agarose.

HF cells were lysed by freeze-thaw cycles in the lysis buffer: $50 \mathrm{mM}$ Tris- $\mathrm{HCl} \mathrm{pH}$ 8.0, $0.5 \mathrm{M}$ $\mathrm{NaCl}, 1 \%$ Tween 20, $1 \mathrm{mM}$ DTT, $10 \%$ glycerol, $10 \mathrm{mM}$ imidazole, containing a proteinase inhibitors cocktail (Roche). The lysate was clarified $(50,000 \mathrm{~g}, 60 \mathrm{~min}, 4 . \mathrm{C})$ and the supernatant was adsorbed onto Ni-NTA agarose. The resin was washed with the buffer: $50 \mathrm{mM}$ Tris- $\mathrm{HCl}, \mathrm{pH} 8.0,0.5 \mathrm{M} \mathrm{NaCl}, 1 \%$ Tween 20,10\% glycerol, $10 \mathrm{mM}$ imidazole and the proteins were eluted with the elution buffer (wash buffer containing $0.25 \mathrm{M}$ imidazole). Eluent was diluted two-fold with the wash buffer and incubated 
with the GSH-agarose beads (Sigma-Aldrich) for $2 \mathrm{~h}$ at $4{ }^{\circ} \mathrm{C}$. After washing out unadsorbed contaminants from the beads, the adsorbed protein was eluted with dialysis buffer containing $10 \mathrm{mM}$ reduced glutathione (Sigma-Aldrich). Collected fractions were dialysed against $25 \mathrm{mM}$ Tris-Cl pH 8.0, $0.1 \mathrm{M} \mathrm{NaCl}, 0.05 \%$ Tween 20, $1 \mathrm{mM}$ DTT, $10 \%$ glycerol and then concentrated on Microcon filters (MWCO $50 \mathrm{kDa}$, Millipore), aliquoted and kept frozen at $-80{ }^{\circ} \mathrm{C}$.

The applied procedure allowed to obtain the recombinant JAK2 (rGST-His $\left.6_{6}-\mathrm{JAK} 2\right)$ of high purity as judged by SDS PAGE (sodium dodecyl sulfate polyacrylamide gel electrophoresis) [40] and Western blotting using a mouse monoclonal [HIS-1] to 6X His tag alkaline phosphatase-conjugated antibody (Abcam).

The protein concentration was determined using the Protein Assay kit (Bio-Rad) with bovine serum albumin (BSA) as a standard.

\subsection{Successive steps of biosensor preparation}

The biosensor preparation was illustrated in Fig. 1. Gold disk electrodes with $2 \mathrm{~mm}^{2}$ nominal area (Bioanalytical Systems (BAS), West Lafayette, IN) were used for experiments. The electrodes were polished with wet $0.3 \mu \mathrm{m}$ and $0.05 \mu \mathrm{m}$ alumina slurry (Alpha and Gamma Micropolish, Buehler, Lake Bluff, IL, USA) on a flat pad for 5 min each and rinsed repeatedly with Milli-Q water. Electrochemical cleaning was performed in $0.5 \mathrm{M} \mathrm{KOH}$ using $\mathrm{CV}$ technique with a three-electrode configuration. Measuring conditions were as follows: minimum potential $-1.2 \mathrm{~V}$, maximum potential $-0.4 \mathrm{~V}$, scan rate $100 \mathrm{mV} \mathrm{s}^{-1}$, number of cycles: 3, 50 and 10. After finishing electrochemical cleaning, each electrode was washed with Milli-Q water and placed in water (for several minutes, until the next step) to avoid contaminants from air. Next, the electrodes were cleaned in $0.5 \mathrm{M} \mathrm{H}_{2} \mathrm{SO}_{4}$ by scanning in the potential window: from $-0.3 \mathrm{~V}$ to $1.5 \mathrm{~V}$, number of cycles: 3,10 and 3 .

Clean electrodes were immersed in solution of $1.0 \times 10^{-5} \mathrm{M}$ DPTA and $1.0 \times 10^{-3} \mathrm{M}$ NAC in an ethanol/water mixture $(80 / 20, \mathrm{v} / \mathrm{v})$ at the room temperature for $3 \mathrm{~h}$. The modification solutions were put into the tubes. After dipping the electrodes, the tubes were sealed with teflon tape and parafilm in order to avoid solvent evaporation. After modification, the electrodes were washed with an ethanol/water mixture (80/20, v/v) and a chloroform/methanol mixture (1/1, v/v) and were dipped in a copper(II) acetate solution in a chloroform/methanol mixture $(1 / 1, \mathrm{v} / \mathrm{v})$ at room temperature for $3 \mathrm{~h}$. The modification was performed in the tubes sealed with teflon tape and parafilm. After modification, the electrodes were washed with the chloroform/methanol mixture, followed by methanol and finally MilliQ water.

Directly after $\mathrm{Cu}$ (II) immobilization, $10 \mu \mathrm{l}$ droplets of $0.6 \mu \mathrm{M}$ rGST-His $_{6}$-JAK2 solution (in buffer: $25 \mathrm{mM}$ Tris-Cl, pH 8.0, $0.1 \mathrm{M} \mathrm{NaCl}, 0.05 \%$ Tween-20, $10 \%$ glycerol) were aliquoted onto the surface of each electrode. The tubes with electrodes were again sealed with eppendorf test-tube and parafilm and incubated $2 \mathrm{~h}$ at $+4{ }^{\circ} \mathrm{C}$. After incubation, the electrodes were washed and conditioned overnight in buffer (25 mM Tris-Cl, $\mathrm{pH} 8.0,0.1 \mathrm{M} \mathrm{NaCl}, 10 \%$ glycerol) with $1 \%$ (v/v) of methanol. Next, the electrodes were washed with buffer and $0.1 \mathrm{M} \mathrm{KCl}$ aqueous solution, put into a measuring cell with $0.1 \mathrm{M} \mathrm{KCl}$ aqueous solution, and deoxygenated by purging with nitrogen for $15 \mathrm{~min}$.

After verifying the presence of rGST-His $_{6}-\mathrm{JAK} 2$ protein on the surface of the gold electrode by $\mathrm{CV}$ and OSWV techniques, $10 \mu \mathrm{l}$ droplets of inhibitor solution (in buffer: $25 \mathrm{mM}$ Tris-Cl, $\mathrm{pH} 8.0,0.1$ $\mathrm{M} \mathrm{NaCl}, 10 \%$ glycerol and $1 \%$ (v/v) of methanol) were deposited on the top of modified electrode surface. The electrodes were covered and incubated with a $10 \mu \mathrm{l}$ solution of the compounds studied for $30 \mathrm{~min}$ at room temperature. Next, the electrodes were rinsed with buffer and $0.1 \mathrm{M} \mathrm{KCl}$, transfered to the measuring cell containing $0.1 \mathrm{M} \mathrm{KCl}$ aqueous solution, and deoxygenated by purging with nitrogen for $15 \mathrm{~min}$, in order to avoid the presence of oxygen during the electrochemical measurements. The 
potential was cycled from $700 \mathrm{mV}$ to $-300 \mathrm{mV}$ with scan rate $100 \mathrm{mV} \mathrm{s}^{-1}$ for the $\mathrm{CV}$ measurements. OSWV was performed with potential from $700 \mathrm{mV}$ to $-300 \mathrm{mV}$ with a step potential of $1 \mathrm{mV}$, a square wave frequency of $25 \mathrm{~Hz}$, and amplitude of $50 \mathrm{mV}$. Each compound studied was examined in the concentration range from $0.05 \mu \mathrm{M}$ to $0.50 \mu \mathrm{M}$.

\subsection{Electrochemical measurements}

All electrochemical measurements were performed on a potentiostat-galvanostat PGSTAT302N (Autolab, Eco Chemie, Netherlands) with a three-electrode configuration. Potentials were measured versus a $\mathrm{Ag}, \mathrm{AgCl} \mid \mathrm{NaCl}(3 \mathrm{M})$ reference electrode, a platinum wire served as an auxiliary electrode. The BAS gold electrodes were used as working electrodes. CV measurements with electrode incorporated NAC/DPTA-Cu(II)-rGST-His ${ }_{6} \mathrm{JAK}^{-}$SAM were performed in the presence of $0.1 \mathrm{M} \mathrm{KCl}, 0.1 \mathrm{M} \mathrm{NaCl}$, $0.1 \mathrm{M} \mathrm{Na}_{2} \mathrm{SO}_{4}, 0.1 \mathrm{M} \mathrm{NaClO}_{4}$ and $0.1 \mathrm{M} \mathrm{CsCl}$ in order to select the best supporting electrolyte.

Cyclic Voltammetry (CV), Osteryoung Square Wave Voltammetry (OSWV) and Electrochemical Impedance Spectroscopy (EIS) were performed in $0.1 \mathrm{M} \mathrm{KCl}$ or in $0.1 \mathrm{M} \mathrm{KCl}+1 \mathrm{mM}$ $\left[\mathrm{Fe}(\mathrm{CN})_{6}\right]^{3-/ 4-}$.

\section{Results and discussion}

\subsection{The electrochemical characterization of NAC/DPTA-Cu(II)-rGST-His $\sigma_{6}-J A K 2$ self-assembled monolayer}

The course of gold electrode modification was presented in Fig. 1. Each step of modification was monitored by cyclic voltammetry (Fig. 1 SI) and electrochemical impedance spectroscopy (Fig. 2 SI).

The bare gold electrode in $0.1 \mathrm{M} \mathrm{KCl}$ with $1 \mathrm{mM}\left[\mathrm{Fe}(\mathrm{CN})_{6}\right]^{3-14-}$ showed the reversible redox couple $(\Delta \mathrm{Ep}=83 \pm 4 \mathrm{mV})$ and almost a straight line in the Nyquist plot, which is characteristic for the diffusion-limiting step of the electrochemical process. The deposition of the NAC-DPTA SAM caused a decrease of reversibility $(\Delta \mathrm{Ep}=280 \pm 60 \mathrm{mV})$ and increased the electron transfer resistance to $144 \pm 43$ $\mathrm{k} \Omega$. On the other hand, the complexation of $\mathrm{Cu}$ (II) by DPTA slightly improved the reversibility of the redox couple $(\Delta \mathrm{Ep}=196 \pm 34 \mathrm{mV})$ and decreased the electron transfer resistance to $44 \pm 10 \mathrm{k} \Omega$.

In order to keep the right structure and activity of kinase rGST-His ${ }_{6}-\mathrm{JAK} 2$, the presence of detergent in the buffer solution is necessary. Thus, the influence of the following detergents on the stability of sensing monolayer deposited on gold electrode were tested: DDM, CHAPS, Thesis, Tween20, Triton X-100 (data not shown). Among them, Tween-20 displayed no effect. Thus, this detergent was used as the component of the immobilization buffer: $25 \mathrm{mM}$ Tris- $\mathrm{Cl}, 0.1 \mathrm{M} \mathrm{NaCl}, 0.05 \%$ Tween$20,10 \%$ glycerol, $\mathrm{pH} 8.0$.

The immobilization of rGST-His $_{6}-\mathrm{JAK} 2$ to Au-NAC-DPTA-Cu(II) SAM substantially decreased the reversibility of the system (Faradic current was not observed) and increased the electron transfer resistance up to $359 \pm 112 \mathrm{k} \Omega$. These results were in good agreement with those already reported for gold electrode incorporating His $_{6}$-Rio1 protein [32].

The rGST-His 6 -JAK2 deposition via coordination of a hexahistidine tag by DPTA-Cu(II) redox centres was also proved by cyclic voltammetry performed in $0.1 \mathrm{M} \mathrm{KCl}$ (Fig. 2). A $2 \mathrm{~h}$ incubation at 
room temperature NAC/DPTA-Cu(II)-electrodes with $10 \mu$ droplets of $0.6 \mu \mathrm{M}$ rGST-His $_{6}-\mathrm{JAK}_{2}$ solution in buffer deposited on the top of electrode was sufficient for protein immobilization. Even though the reversibility of the system decreased $(\Delta \mathrm{Ep}=87 \pm 34 \mathrm{mV})$, still the $\mathrm{CuII} / \mathrm{CuI}$ redox couple was well recognized, with reduction and oxidation peaks at $0.247 \pm 0.022$ and $0.334 \pm 0.023 \mathrm{mV}(\mathrm{n}=$ $60)$, respectively.

The immobilization of rGST-His $_{6}-\mathrm{JAK} 2$ on the redox active layer was also controlled with OSWV (Fig. 3). The intensity of $\mathrm{Cu}$ (II) redox current for electrodes modified by NAC/DPTA-Cu(II) and NAC/DPTA-Cu(II)-rGST-His ${ }_{6}$-JAK2 were $2.56 \pm 0.83 \mu \mathrm{A}(\mathrm{n}=48 / 60$, reproducibility $80 \%)$ and $1.46 \pm 0.31 \mu \mathrm{A}(\mathrm{n}=78 / 115$, reproducibility $68 \%)$. These data allow to estimate a decrease of the $\mathrm{Cu}(\mathrm{II})$ redox current upon rGST-His 6 -JAK2 immobilization at the $43 \%$ level.

In order to check the influence of the supporting electrolyte on the electrochemical properties of gold electrodes incorporating a NAC/DPTA-Cu(II)-rGST-His ${ }_{6}-\mathrm{JAK} 2$ monolayer, CV measurements were performed in the presence of $0.1 \mathrm{M}$ solution of: $\mathrm{CsCl}, \mathrm{KCl}, \mathrm{NaCl}, \mathrm{Na}_{2} \mathrm{SO}_{4}$ and $\mathrm{NaClO}_{4} . \mathrm{CV}$ measurements at the scan rate from $10 \mathrm{mV} \mathrm{s}^{-1}$ up to $1000 \mathrm{mV} \mathrm{s}^{-1}$ were also performed (Fig. 4, Fig. $3 \mathrm{SI}$ ). The suitability of electrolytes was in the following order:

$\mathrm{CsCl} \geq \mathrm{KCl}>\mathrm{NaCl}>\mathrm{Na}_{2} \mathrm{SO}_{4} \geq \mathrm{NaClO}_{4}$

The best defined peaks of $\mathrm{CuII} / \mathrm{CuI}$ were observed in the presence of $\mathrm{CsCl}$. The plot of the anodic and cathodic peak currents versus scan rates showed a linear relationship up to $1000 \mathrm{mV} \mathrm{s}^{-1}$ (Fig. 3A SI). This confirms that the observed redox activity comes from $\mathrm{Cu}(\mathrm{II})$ redox centres located on electrode surface. The electron transfer coefficients $(\alpha)$ and the electron transfer rate constants $(\mathrm{k})$ were calculated based on the generally applicable Laviron's equation [41] and collected in Table 1. The values of $\alpha$ measured in the presence of $\mathrm{CsCl}$ and $\mathrm{KCl}, 0.21 \pm 0.08$ and $0.19 \pm 0.09$, respectively, were lower than 0.5 . This indicates that the energy activation for electron transfer is lower for reduction than for oxidation process [41]. The electron rate constant shows how the redox couple is kinetically facile. This means that the systems possessing a small value of $\mathrm{k}$ reach equilibrium slower than systems possessing a larger value of $\mathrm{k}$ [37]. The $\mathrm{k}$ values were $1.06 \pm 0.33 \mathrm{~s}^{-1}$ and $1.36 \pm 0.29 \mathrm{~s}^{-1}$ for $\mathrm{CsCl}$ and $\mathrm{KCl}$, respectively (Table 1).

The calculation of the $\alpha$ and $\mathrm{k}$ parameters was not possible when $\mathrm{NaCl}, \mathrm{Na}_{2} \mathrm{SO}_{4}$ and $\mathrm{NaClO}_{4}$ were applied as the supporting electrolyte. The reduction and oxidation peaks were wide and barely visible (Fig. 3B-D SI). The presence of cations can affect the redox activity of copper(II) in the SAM, with the peak current decreasing in the sequence:

$\mathrm{Cs}^{+}>\mathrm{K}^{+}>\mathrm{Na}^{+}$

So, it might be concluded that in the case of chloride salts, their suitability for getting the best redox parameters of NAC/DPTA-Cu(II)-rGST-His 6 -JAK2 SAM increases with an increase of the cation lipophilicity (Table 1, Fig. 4, Fig. 3A and B SI), which is consistent with the Hofmeister series [42]. A similar trend was observed for the electrochemical properties of cytochrome c studied in a range of different chloride salts [43]. The best Faradaic current was recorded in the presence of $\mathrm{CsCl}$.

Since the CuII/CuI couple involves the transfer of a single electron per molecule, the charge $\mathrm{Q}$ calculated based on the integration of the voltammetric peaks of the cyclic voltammograms recorded at a scan rate of $100 \mathrm{mV} \mathrm{s}^{-1}$ (Fig. 4, Fig. 3A SI) was used for obtaining the $\mathrm{Cu}$ (II) surface coverage values $(\Gamma)$ according to the equation [37]:

$\Gamma=\mathrm{Q} / \mathrm{nFA}$

where $\mathrm{A}$ is the real surface area of gold electrode $\left(0.032 \mathrm{~cm}^{2}\right), \mathrm{F}$ is the Faraday constant $\left(96,485^{\circ} \mathrm{C}\right), \mathrm{n}$ is the numbers of electrons transferred $(n=1)$ and $\Gamma$ is the surface coverage. The obtained value, in the range of $2.0 \times 10^{-10} \mathrm{~mol} \mathrm{~cm} \mathrm{~cm}^{-2}$ (Table 1), was in a good agreement with those already reported for other redox active SAMs $[36,44]$. 
Based on the above results, for the next electrochemical measurements $0.1 \mathrm{M} \mathrm{KCl}$ solution was selected. The electrochemical parameters of NAC/DPTA-Cu(II)-rGST-His ${ }_{6}-\mathrm{JAK} 2$ SAM observed in its presence were sufficient and only a little worse in comparison to these obtained in the presence of $\mathrm{CsCl}$. In addition, $\mathrm{KCl}$ is more suitable for keeping the biological activity of proteins in comparison to $\mathrm{CsCl}$.

\subsection{Electrochemical exploration of the interactions between rGST-His ${ }_{6}$-JAK2 immobilized on the electrode surface via NAC/DPTA-Cu(II) complex and inhibitors present in the solution}

The biosensor proposed was used for electrochemical screening of interactions between JAK2 kinase and known inhibitors, potential inhibitors (berberines), as well as with caffeic acid, used as a control compound which has no affinity to JAK2 kinase. The berberines, a class of isoquinoline alkaloids, were selected for this study because of their wide potential therapeutic properties [45]. Their ability for inhibition of kinases catalytic activity has been also reported [46]. The chemical structures of all compounds studied are collected in Table 2.

OSWV technique was chosen for exploring rGST-His 6 -JAK2-inhibitor interactions. This technique allows to reduce the capacitive current. The solutions of potential inhibitors were prepared in the concentration range from $0.05 \mu \mathrm{M}$ to $0.50 \mu \mathrm{M}$. With the increasing concentration of compounds studied the $\mathrm{Cu}$ (II) redox peak current decreased. The representative OSWVs recorded in the presence of Erlotinib (the strongest known inhibitor), palmatine (an isoquinolone alkaloid potential inhibitor) and caffeic acid (control compound) were presented in Fig. 5.

The linear relationships between the relative $\mathrm{Cu}$ (II) redox current decrease vs. concentration of the studied compound were observed in the range from $0.05 \mu \mathrm{M}$ to $0.20 \mu \mathrm{M}$. In the range from $0.20 \mu \mathrm{M}$ to $0.50 \mu \mathrm{M}$ the signals were changed only a little (Fig. 6, Fig. 4SI).

Therefore, the relative decrease of the $\mathrm{Cu}(\mathrm{II})$ current measured at the lowest concentration $(0.05$ $\mu \mathrm{M}$ ), as well as at $0.20 \mu \mathrm{M}$ where some kind of "breaking point" occurred were selected for estimation of the strength of the interaction. In addition, parameter $b$ from the regression equations calculated for the $0.05 \mu \mathrm{M}$ to $0.20 \mu \mathrm{M}$ range, were taken into account (Table 2). These three parameters allow to arrange all compounds studied from the highest to the lowest values. The highest values indicated the strongest interactions, which were observed for know inhibitors Erlotinib and Fasudil [47,48]. Strong

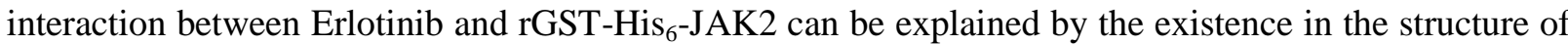
an inhibitor aniline-pyrimidine scaffold. These chemotypes are known as promising kinase inhibitors [49]. The values recorded for palmatine and Tyrphostin AG-490 a well know inhibitor[47], were comparable. This indicated that an isoquinolone alkaloid (palmatine) could be explored in the future as a potential kinase inhibitor, for example with using electrochemical approaches developed by $\mathrm{Li}$ and coworkers destined for determination of kinase phosphorylation activity [20-23]. The presence of a methyl-benzene substitution in the 13-benzylpalmatine structure substantially decreased the strength of its interaction with rGST-His $_{6}-\mathrm{JAK} 2$ (Table 2). We can underline, that for caffeic acid, the control compound, which has no affinity to kinase JAK2, very low values for all three proposed parameters were observed. This indicated that the analytical system based on NAC/DPTA-Cu(II)-rGST-His ${ }_{6}-\mathrm{JAK} 2$ was selective, and therefore can be applied for screening compounds which might act as the potential kinase inhibitors. 


\section{Conclusions}

The biosensor based on a NAC/DPTA-Cu(II)-rGST-His ${ }_{6}$-JAK2redox active layer was successfully applied for electrochemical screening of the interactions between rGST-His $_{6}-$ JAK$_{2}$ protein and selected compounds. The DPTA-Cu(II) complex deposited onto the electrode surface plays a double role, both as units for immobilization of rGST-His $_{6}-\mathrm{JAK}_{2}$, as well as transduction centres tracking the kinase-selected compound interactions.

The proposed analytical tool was very sensitive. Analytical signals were observed in the concentration range from $0.05 \mu \mathrm{M}$ to $0.20 \mu \mathrm{M}$. The strongest biosensor responses were observed in the presence of known kinase inhibitors. Caffeic acid, a control compound, which has no affinity to kinase JAK2, generated very low responses. These results confirmed selectivity of biosensor presented. The response of one of the new compounds tested, a berberine analogue (isoquinolone alkaloid) was comparable to the responses of Tyrphostin AG-490 kinase inhibitor. This indicates that this berberine derivative could be explored further as a naturally occurring potential kinase inhibitor.

Taking into account the above parameters, the biosensor presented could be applied as a suitable analytical tool for screening new potential kinase inhibitors.

\section{Acknowledgements}

This work was supported by Grant Polish Ministry of Sciences and Higher Education No NN302 178 238 and No679/N-Belgium/2010/0, COST Action CM10005 "SupramolecularChemistry in Water" and Institute of Animal Reproduction and Food Research of the Polish Academy of Sciences, Olsztyn, Poland.

\section{References}

[1] N.K. Williams, R.S. Bamert, O. Patel, Ch. Wang, P.M. Walden, A.F. Wilks, E. Fantino, J. Rossjohn, I.S. Lucet, Dissecting specificity in the Janus kinases: the structures of JAK-specific inhibitors complexed to the JAK1 and JAK2 proteintyrosine kinase domains, J. Mol. Biol. 387 (2009) 219-232.

[2] A. Verma, S. Kambhampati, S. Parmar, L.C. Platanias, Jak family of kinases in cancer, Cancer Metastasis Rev. 22 (2003) 423-434.

[3] M.M. Seavey, P. Dobrzanski, The many faces of Janus kinase, Biochem. Pharm. 83 (2012) 11361145 .

[4] M.D. Godney, P.P. Sayeski, Jak2 tyrosine kinase and cancer: how good cells get HiJAKed, AntiCancer Agents Med. Chem. 7 (2007) 643-650.

[5] F.O.S. Santos, S. Verstovsek, AK2 inhibitors: what's the true therapeutic potential? Blood Rev. 25 (2011) 53-63.

[6] Y. Sun, L. Moretti, N.J. Giacalone, S. Schleicher, S.K. Speirs, A.P. Carbone, B. Lu, Inhibition of JA2 signaling by TG101209 enhances radiotherapy in lung cancer models, J. Thorac. Oncol. 6 (2011) 699-706.

[7] Y. Kawai, M. Sato, Y. Umezawa, Single color fluorescent indicators of proteinphosphorylation for multicolor imaging of intracellular signal flow dynamics, Anal. Chem. 76 (2004) 6144-6149. 
[8] Y. Umezawa, Genetically encoded optical probes for imaging cellular signalingpathways, Biosens. Bioelectron. 20 (2005) 2504-2511.

[9] M. Vestergaard, K. Kerman, E. Tamiya, An overview of label-free electrochemical protein sensors, Sensors 7 (2007) 3442-3458.

[10] P. Stenlund, A. Frostell-Karlsson, O.P. Karlsson, Studies of small molecule interactions with protein phosphatases using biosensor technology, Anal. Biochem. 353 (2006) 217-225.

[11] T. Yoshida, M. Sato, T. Ozawa, Y. Umezawa, An SPR-based screening method for agonist selectivity for insulin signaling pathways based on the binding of phosphotyrosine to its specific binding protein, Anal. Chem. 72 (2000) 6-11.

[12] M. Sato, T. Ozawa, K. Inukai, T. Asano, Y. Umezawa, Fluorescent indicators for imaging protein phosphorylation in single living cells, Nat. Biotechnol. 20(2002) 287-294.

[13] C.-A. Chen, R.H. Yeh, X. Yan, D.S. Lawrence, Biosensors of protein kinase action: from in vitro assays to living cells, Biochim. Biophys. Acta 1697 (2004) 39-51.

[14] K. Kerman, M. Chikae, S. Yamamura, E. Tamiya, Gold nanoparticle-based electrochemical detection of protein phosphorylation, Anal. Chim. Acta 588 (2007) 26-33.

[15] K. Kerman, M. Vestergaard, E. Tamiya, Label-free electrical sensing of small molecule inhibition on tyrosine phosphorylation, Anal. Chem. 79 (2007) 6881-6885.

[16] Y. Guo, J.H. Chen, C. Guonan, A label-free electrochemical biosensor for detection of HIV related gene based on interaction between DNA and protein, Sens. Actuators, B 184 (2013) 113-117.

[17] B. Prieto-Simón, M. Cortina, M. Campas, C. Calas-Blanchard, Electrochemical biosensors as a tool for antioxidant capacity assessment, Sens. Actuators, B 129(2008) 459-466.

[18] Z. Altintas, I. Tothill, Biomarkes and biosensors for the early diagnosis of lung cancer, Sens. Actuators, B 188 (2013) 988-998.

[19] L.-J. Feng, X.-H. Zhang, D.-M. Zhao, S.-F. Wang, Electrochemical studies of bovine serum albumin immobilization onto the poly-o-phenylenediamine and carbon-coated nickel composite film and its interaction with papaverine, Sens. Actuators, B 152 (2011) 88-93.

[20] J. Wang, Y. Cao, Y. Li, Z. Liang, G. Li, Electrochemical strategy for detection of phosphorylation based on enzyme-linked electrocatalysis, J. Electroanal. Chem. 656 (2011) 274-278.

[21] P. Miao, L. Ning, X. Li, P. Li, G. Li, Electrochemical strategy for sensing protein phosphorylation, Bioconjug. Chem. 23 (2012) 141-145.

[22] J. Wang, M. Shen, Y. Cao, G. Li, Switchable, On-off electrochemical technique for detection of phosphorylation, Biosens. Bioelectron. 26 (2010) 638-642.

[23] H. Xiao, J. Wang, G. Chen, G. Li, Electrochemical evaluation of self-disassociation of PKA upon activation by cAMP, Langmuir 23 (2007) 3506-3508.

[24] H. Chen, Q. Mei, Y. Hou, K. Koh, J. Lee, B. Chen, L. Fanh, X. Zhao, Buildinga sensitive immunosensing platform based on oriented immobilization of histidine-tagged antibody on $\mathrm{NiO}$ decorated SWNTs, Sens. Actuators, B 181(2013) 38-43.

[25] S. Chebil, A. Miodek, V. Ambike, H. Sauriat-Dorizon, C. Policar, H. Korri-Youssoufil, Polypyrrole functionalized with new copper complex as platform for His-tag antibody immobilization and direct antigen detection, Sens. Actuators, B 185 (2013) 762-770.

[26] A. Jargiło, I. Grabowska, H. Radecka, M. Sulima, I. Marszałek, A. Wysłouch-Cieszyńska, W. Dehaen, J. Radecki, Redox active dipyrromethene-Cu(II) monolayer for oriented immobilization of Histagged RAGE domains - the baseof electrochemical biosensor for determination of Ab16-23, Electroanalysis 25(2013) 1185-1193.

[27] J.F. Hainfeld, W. Liu, C.M.R. Halsey, P. Freimuth, R.D. Powell, Ni-NTA-gold clusters target Histagged proteins, J. Struct. Biol. 127 (1999) 185-198.

[28] C. Ley, D. Holtmann, K.-M. Mangold, J. Schrader, Immobilization of histidine-

tagged proteins on electrodes, Colloids Surf., B 88 (2011) 539-551. 
[29] Z. Hubicki, A. Jakowicz, Studies on sorption of copper(II) complexes with IDA and NTA acids on strongly and weakly basic anion exchangers, Desalination155 (2003) 121-130.

[30] I. Hafaid, S. Chebil, H. Korri-Youssoufi, F. Bessueille, A. Errachid, Z. Sassi, Z. Ali, A. Abdelhani, N. Jaffrezic-Renault, Effect of electrical conditions on an impedimetric immunosensor based on a modified conducting polypyrrole, Sens. Actuators, B 144 (2010) 323-331.

[31] M.A. Rogers, J.B.C. Findlay, P.A. Millner, Lipocalin based biosensors for low mass hydrophobic analytes; development of a novel SAM for polyhistidine tagged proteins, Sens. Actuators, B 150 (2010) $12-18$.

[32] J. Maly, M. Ilie, V. Foglietti, E. Cianci, A. Minotti, L. Nardi, A. Masci, W. Vastarella, R. Pilloton, Continuous flow micro-cell for electrochemical addressing of engineered biomolecules, Sens. Actuators, B 111-112 (2005) 317-322.

[33] Y.T. Lim, K.Y. Lee, K. Lee, B.H. Chung, Immobilization of histidine-tagged proteins by magnetic nanoparticles encapsulated with nitrilotriacetic acid (NTA)-phospholipids micelle, Biochem. Biophys. Res. Commun. 344 (2006) 926-930.

[34] D. Kröger, M. Liley, W. Schiweck, A. Skerra, H. Vogel, Immobilization of histidine-tagged proteins on gold surfaces using chelator thioalkanes, Biosens. Bioelectron. 14 (1999) 155-161.

[35] E. Mikuła, M. Sulima, I. Marszałek, A. Wysłouch-Cieszyńska, P. Verwilst, W. Dehaen, J. Radecki, H. Radecka, Oriented immobilization of His-tagged protein on a redox active thiol derivative of DPTA$\mathrm{Cu}$ (II) layer deposited on a gold electrode - the base of electrochemical biosensors, Sensors 13 (2013) 1158-11602.

[36] M. Mielecki, J. Wojtasik, M. Zborowska, K. Kurzątkowska, K. Grzelak, W. Dehaen, J. Radecki, H. Radecka, Oriented immobilization of His-tagged kinaseRIO1 protein on redox active N-(IDA-like)$\mathrm{Cu}$ (II) monolayer deposited on gold electrode-the base of electrochemical biosensor, Electrochim. Acta 96 (2013) 147-154.

[37] J.R. Hart, Ethylenediaminetetraacetic Acid and Related Chelating Agents in Ullmann's Encyclopedia of Industrial Chemistry, Wiley-VCH, Weinheim, 2000, pp. 573-578.

[38] V.V. Fomenko, T.N. Polynova, M.A. Porai-Koshits, G.L. Varlamova, N.I. Pechurova, Crystal structure of copper(II) diethylenetriaminepentaacetatemonohydrate, J. Struct. Chem. 14 (1973) 529.

[39] Z.A. Siddiqi, S. Noor, M. Shahid, M. Khalid, Spectral, thermal and electrochemical characterization of novel homo-dinuclear complexes [M2(H3DTPA)(H2O)6]Cl2 $\times \mathrm{xH}_{2} \mathrm{O}(\mathrm{M}=\mathrm{Cr} 2+$, Mn2+, Co2+, Ni2+or Cu2+), Spectrochim. Acta, Part A 78 (2011) 1386-1391.

[40] U.K. Laemmli, Cleavage of structural proteins during the assembly of the head of bacteriophage T4, Nature 227 (1970) 680-685.

[41] A.J. Bard, L.R. Faulkner, Electrochemical Methods-Fundamentals and Applications, second ed., John Wiley\& Sons, Inc., Hoboken, NJ, 2001.

[42] F. Hofmeister, Zur Lehre von der Wirkung der Salze, Arch. Exp. Pathol. Pharmakol. 24 (1888) $247-260$.

[43] L. Medda, A. Salis, E. Magner, Specific ion effects on the electrochemical properties of cytochrome c, Phys. Chem. Chem. Phys. 14 (2012) 2875-2883.

[44] I. Szymańska, M. Stobiecka, Cz. Orlewska, T. Rohand, D. Janssen, W. Dehaen, H. Radecka, Electroactive dipyrromethene- $\mathrm{Cu}$ (II) self-assembled monolayers: complexation reaction on the surface of gold electrodes, Langmuir 24 (2008) 11239-11245.

[45] K. Bhadra, G.S. Kumar, Therapeutic potential of nucleic acid-binding isoquinoline alkaloids: binding aspects and implications for drug design, Med. Res. Rev. 31 (2011) 821-862.

[46] M. Jang, M. Jwa, J.H. Kim, K. Song, Selective inhibition of MAPKK Wis1 in the stress-activated MAPK cascade of schizosaccharomyces pombe by novel berberine derivatives, J. Biol. Chem. 277 (2002) 12388-12395. 
[47] A. Markopoulou, V.C. Kyttaris, Small molecules in the treatment of systemic lupus erythematosus, Clin. Immunol. 148 (2013) 359-368.

[48] Z. Li, M. Xu, S. Xing, W.T. Ho, T. Ishii, Q. Li, X. Fu, Z.J. Zhao, Erlotinib effectively inhibits JAK2V617F activity and polycythemia vera cell growth, J. Biol. Chem. 282(2007) 3428-3432.

[49] A. Poulsen, A. William, S. Blanchard, H. Nagaraj, M. Williams, H. Wang, A. Lee, E. Sun, E.-L. Teo, E. Tan, K.C. Goh, B. Dymock, Structure-based design of nitrogen-linked macrocyclic kinase inhibitors leading to the clinical candidate SB1317/TG02, a potent inhibitor of cyclin depedant kinase (CDKs), Janus kinase 2 (JAK2), and Fms-like tyrosine kinase-3 (FLT3), J. Mol. Model. 19 (2013) 119130.

Table 1. The electron transfer coefficient $\alpha$, the electron transfer rate constant $k$ and surface coverage $\Gamma$ values estimated based on the $\mathrm{CV}$ recorded for a gold electrode modified with NAC-DPTA-Cu(II)- $r \mathrm{His}_{6}-\mathrm{Jak}_{2}$ in the presence of $0.1 \mathrm{M} \mathrm{KCl}$ and $0.1 \mathrm{M} \mathrm{CsCl}$.

\begin{tabular}{|l|l|l|l|l|}
\hline Electrolyte $[\mathbf{0 . 1 ~ M}]$ & $\boldsymbol{\alpha}$ & $\boldsymbol{k}\left[\boldsymbol{s}^{-1}\right]$ & $\boldsymbol{\Gamma}_{\text {ox. }}\left[\mathbf{m o l} \times \mathbf{c m}^{-2}\right]$ & $\boldsymbol{\Gamma}_{\text {red. }}\left[\mathbf{m o l} \times \mathbf{c m}^{-2}\right]$ \\
\hline KCl & $0.19 \pm 0.09$ & $1.36 \pm 0.29$ & $(1.59 \pm 0.43) \times 10^{-10}$ & $(1.56 \pm 0.80) \times 10^{-10}$ \\
\hline CsCl & $0.21 \pm 0.08$ & $1.06 \pm 0.33$ & $(1.81 \pm 0.31) \times 10^{-10}$ & $(1.86 \pm 0.51) \times 10^{-10}$ \\
\hline
\end{tabular}


Table 2. The estimation of interactions strength between $r \mathrm{His}_{6}-\mathrm{Jak} 2$ kinase and compounds studied based on relative decrease of $\mathrm{Cu}^{\mathrm{II} / \mathrm{I}}$ redox current measured at 0.05 and $0.20 \mu \mathrm{M}(\mathrm{n}=7-9)$.

\begin{tabular}{|c|c|c|c|c|c|}
\hline & $\begin{array}{c}\text { name } \\
\text { of compound }\end{array}$ & structure & $\begin{array}{c}\mathrm{I}_{0.05 \mu \mathrm{M}} / \mathrm{I}_{\mathrm{o}} \mathrm{X} \\
100 \%[\%]\end{array}$ & $\begin{array}{c}\mathrm{I}_{0.20 \mu \mathrm{M}} / \mathrm{I}_{\mathrm{o}} \mathrm{x} \\
100 \%[\%]\end{array}$ & $\begin{array}{l}\text { parameter "b" } \\
\text { of regression } \\
\text { equation of } \\
\text { relative } \mathrm{Cu}^{\mathrm{II} / \mathrm{I}} \\
\text { current }[\%] \\
\text { vs. } \mathrm{C} \text { in range: } \\
0.05-0.20 \mu \mathrm{M}\end{array}$ \\
\hline 1 & Erlotinib & $\mathrm{H}^{3} \mathrm{C}^{-}$ & $-35.84 \pm 4.85$ & $-51.72 \pm 3.91$ & -31.4 \\
\hline 2 & Fasudil & & $-30.14 \pm 9.15$ & $-51.89 \pm 9.47$ & -22.8 \\
\hline 3 & Tasocitinib & & $-19.97 \pm 4.16$ & $-32.24 \pm 4.83$ & -17.2 \\
\hline 4 & Lestaurtinib & & $-16.37 \pm 6.02$ & $-44.18 \pm 4.71$ & -9.2 \\
\hline 5 & $\begin{array}{l}\text { Tyrphostin } \\
\text { AG-490 }\end{array}$ & & $-16.08 \pm 2.65$ & $-40.97 \pm 2.54$ & -9.1 \\
\hline 6 & Berberine R8 & & $-13.55 \pm 4.54$ & $-31.48 \pm 3.63$ & -8.3 \\
\hline 7 & K252a & & $-11.84 \pm 4.51$ & $-41.38 \pm 7.40$ & -2.9 \\
\hline 8 & Berberine R9 & & $-9.07 \pm 3.43$ & $-31.21 \pm 6.78$ & -2.8 \\
\hline 9 & Caffeic Acid & & $-1.31 \pm 2.61$ & $-16.25 \pm 2.81$ & +3.44 \\
\hline
\end{tabular}



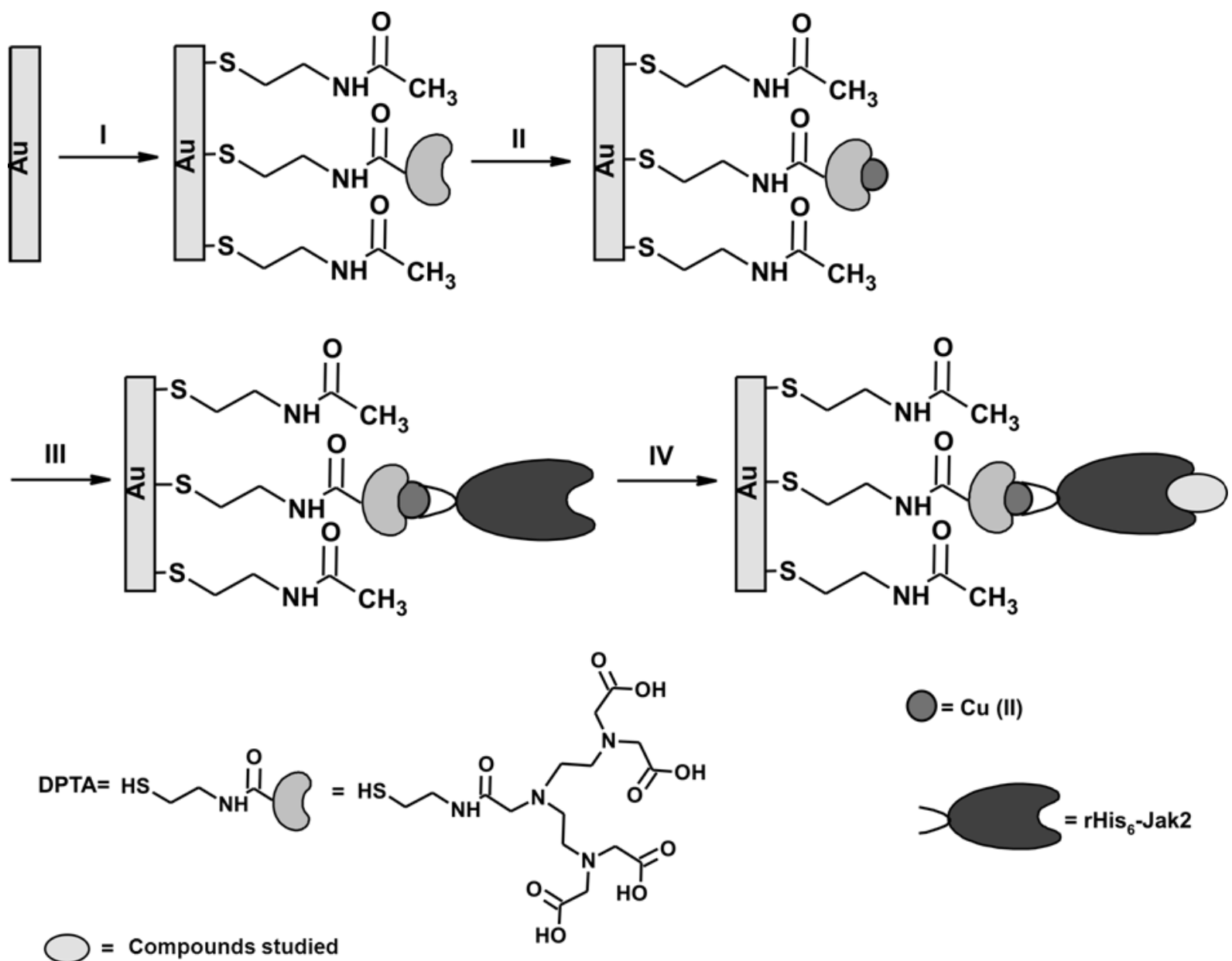

Fig. 1. Scheme of biosensor preparation. 


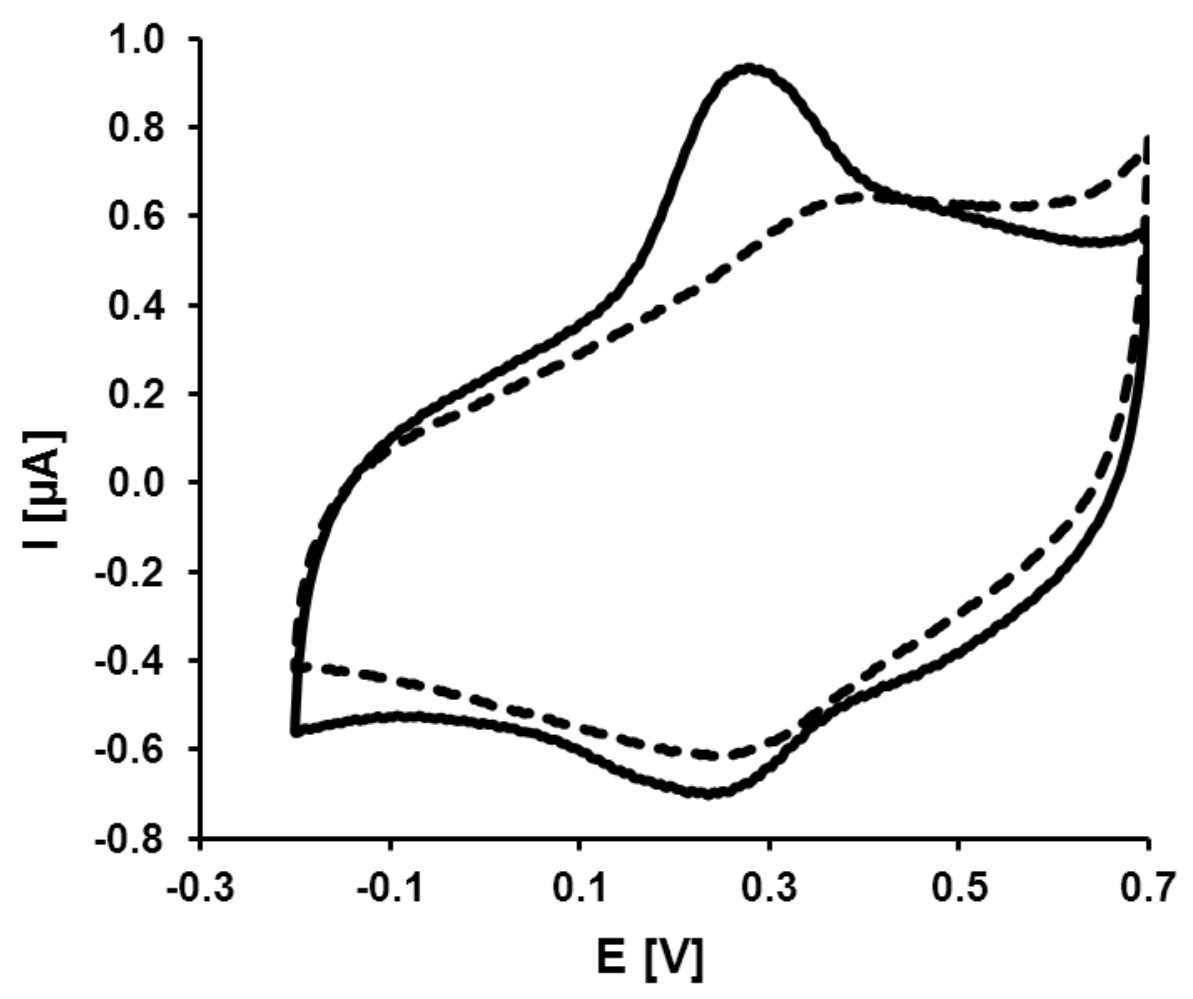

Fig. 2. The cyclic voltammogram (CV) curves obtained for electrodes modified by NAC/DPTA-Cu(II) (solid line) and NAC/DPTA-Cu(II)-rGST-His 6 -JAK2 (dotted line). Measuring conditions: scan rate 100 $\mathrm{mV} \mathrm{s}^{-1}$, reference electrode $\mathrm{Ag} / \mathrm{AgCl}$, counter electrode $\mathrm{Pt}$, solution composition: $0.1 \mathrm{M} \mathrm{KCl}$. 


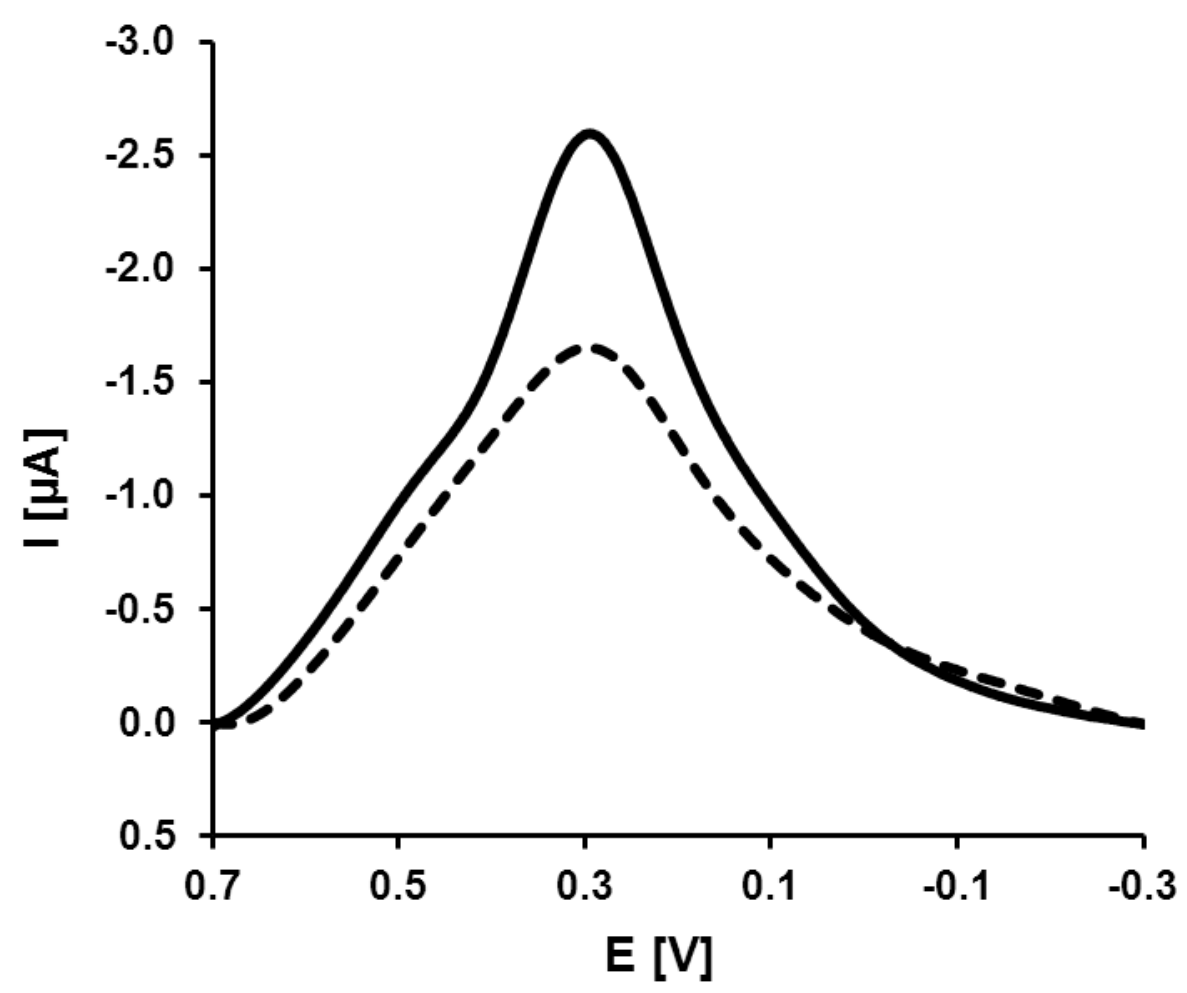

Fig. 3. OSWV voltammograms obtained for electrodes modified by NAC/DPTA-Cu(II) (solid line) and NAC/DPTA-Cu(II)-rGST-His ${ }_{6}-\mathrm{JAK} 2$ (dotted line). Measuring conditions: amplitude $50 \mathrm{mV}$, reference electrode $\mathrm{Ag} / \mathrm{AgCl}$, counter electrode $\mathrm{Pt}$, solution composition: $0.1 \mathrm{M} \mathrm{KCl}$. 


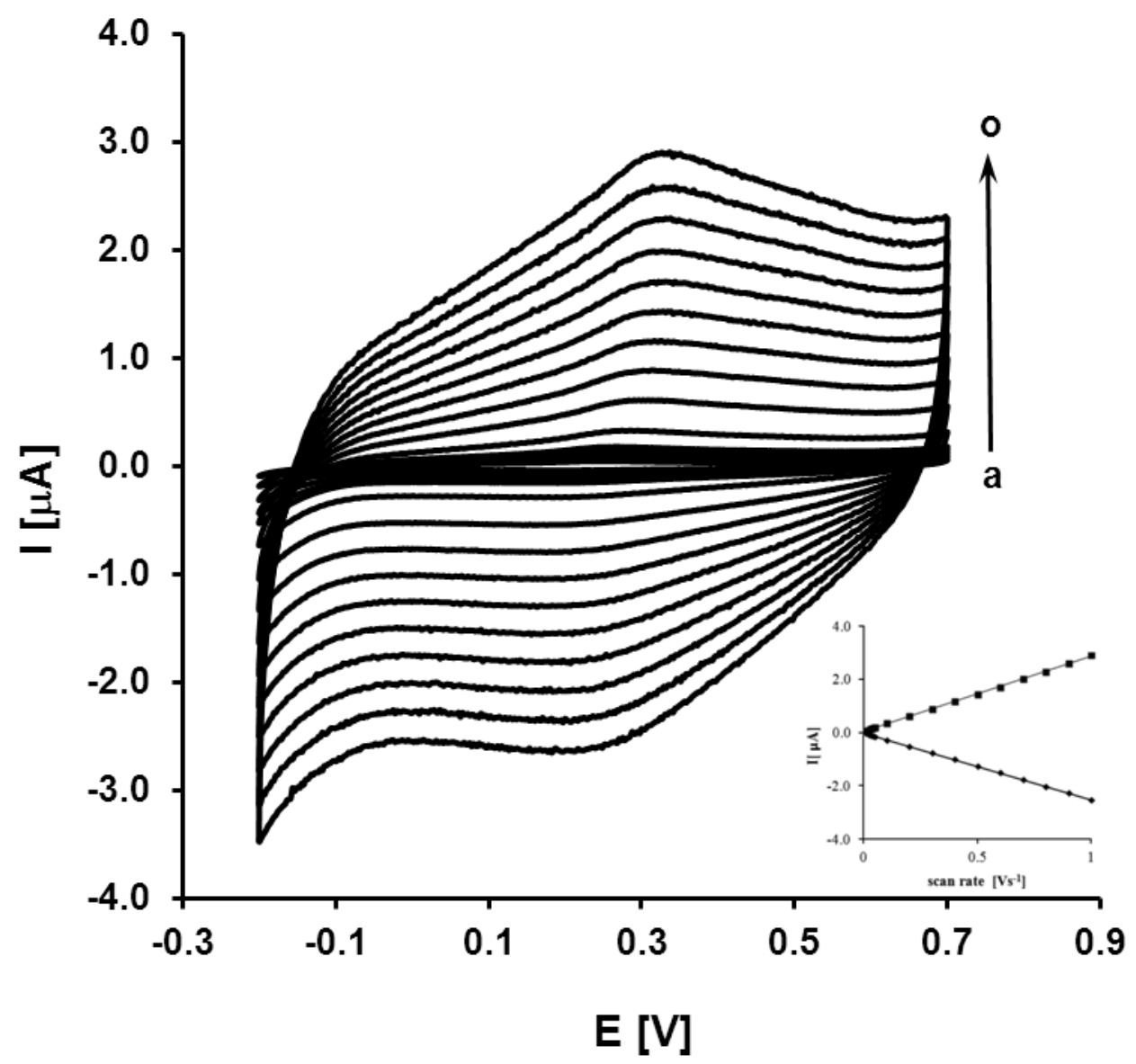

Fig. 4. Cyclic voltammograms of rGST-His $_{6}-\mathrm{JAK} 2-\mathrm{Cu}(\mathrm{II})-\mathrm{IDA} / \mathrm{NAC}-\mathrm{Au}$ electrode measured at different scan rate. Scan rates: (a) $10 \mathrm{mV} \mathrm{s}^{-1}$, (b) $20 \mathrm{mV} \mathrm{s}^{-1}$, (c) $30 \mathrm{mV} \mathrm{s}^{-1}$, (d) $40 \mathrm{mV} \mathrm{s}^{-1}$, (e) $50 \mathrm{mV} \mathrm{s}^{-1}$, (f) $100 \mathrm{mV} \mathrm{s}^{-1}$, (g) $200 \mathrm{mV} \mathrm{s}^{-1}$, (h) $300 \mathrm{mV} \mathrm{s}^{-1}$, (i) $400 \mathrm{mV} \mathrm{s}^{-1}$, (j) $500 \mathrm{mV} \mathrm{s}^{-1}$, (k) $600 \mathrm{mV} \mathrm{s}^{-1}$, (l) 700 $\mathrm{mV} \mathrm{s}^{-1}$, (m) $800 \mathrm{mV} \mathrm{s}^{-1}$, (n) $900 \mathrm{mV} \mathrm{s}^{-1}$, (o) $1000 \mathrm{mV} \mathrm{s}^{-1}$. Measuring conditions: scan rates $10-1000 \mathrm{mV}$ $\mathrm{s}^{-1}$, reference electrode $\mathrm{Ag} / \mathrm{AgCl}$, counter electrode Pt. Solution composition: $0.1 \mathrm{M} \mathrm{KCl}$. Inset: Plot of anodic $(\bullet$, Ipa) and cathodic $(\boldsymbol{\bullet}$, Ipc) peak current against potential scan rates. 


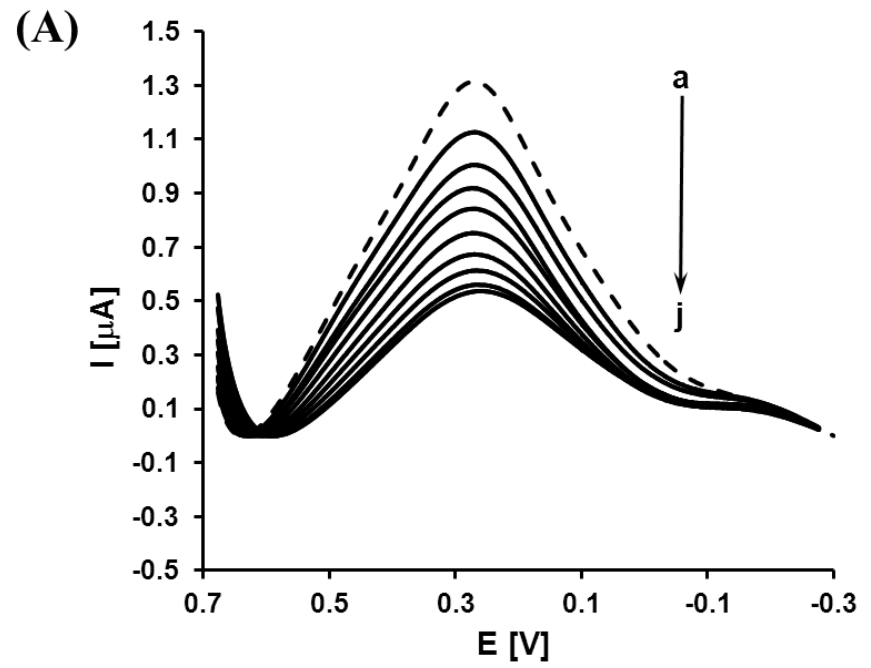

(B)

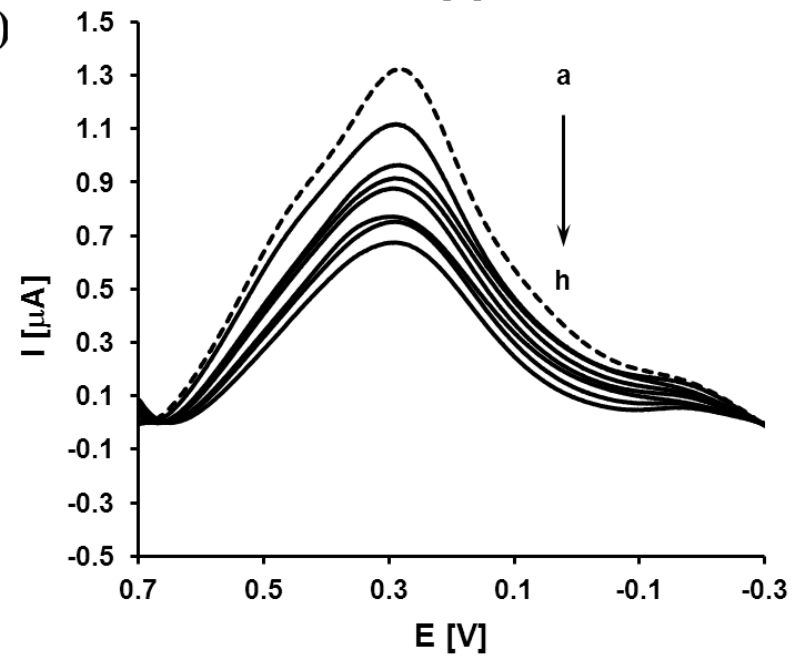

(C)

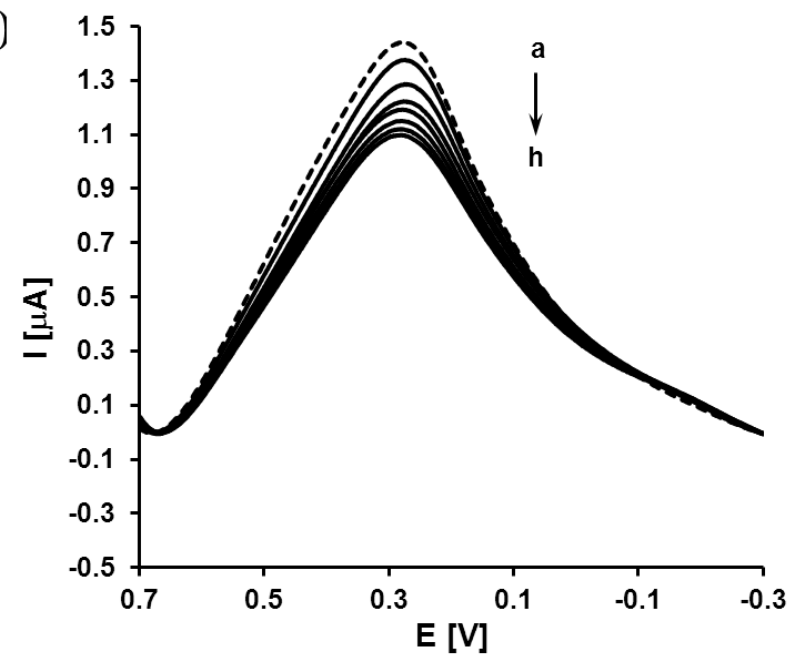

Fig. 5. Osteryoung square wave voltammetry (OSWV) recorded with gold electrode incorporated NAC/DPTA-Cu(II)-rGST-His ${ }_{6}-\mathrm{JAK} 2$ in the presence of: (A) Erlotinib, (B) Palmatine, (C) Caffeic Acid. Measuring conditions: scan rate $100 \mathrm{mV} \mathrm{s}^{-1}$, reference electrode $\mathrm{Ag} / \mathrm{AgCl}$, counter electrode $\mathrm{Pt}$, solution composition: $0.1 \mathrm{M} \mathrm{KCl}$. Concentration of Erlotinib: (a) $0.00 \mu \mathrm{M}$, (b) $0.01 \mu \mathrm{M}$, (c) $0.03 \mu \mathrm{M}$, (d) 0.05 $\mu \mathrm{M}$, (e) $0.10 \mu \mathrm{M}$, (f) $0.15 \mu \mathrm{M}$, (g) $0.20 \mu \mathrm{M}$, (h) $0.30 \mu \mathrm{M}$, (i) $0.40 \mu \mathrm{M}$, (j) $0.50 \mu \mathrm{M}$; concentration of caffeic acid and Palmatine: (a) $0.00 \mu \mathrm{M}$, (b) $0.05 \mu \mathrm{M}$, (c) $0.10 \mu \mathrm{M}$, (d) $0.15 \mu \mathrm{M}$, (e) $0.20 \mu \mathrm{M}$,(f) 0.30 $\mu \mathrm{M}$, (g) $0.40 \mu \mathrm{M}$, (h) $0.50 \mu \mathrm{M}$. 


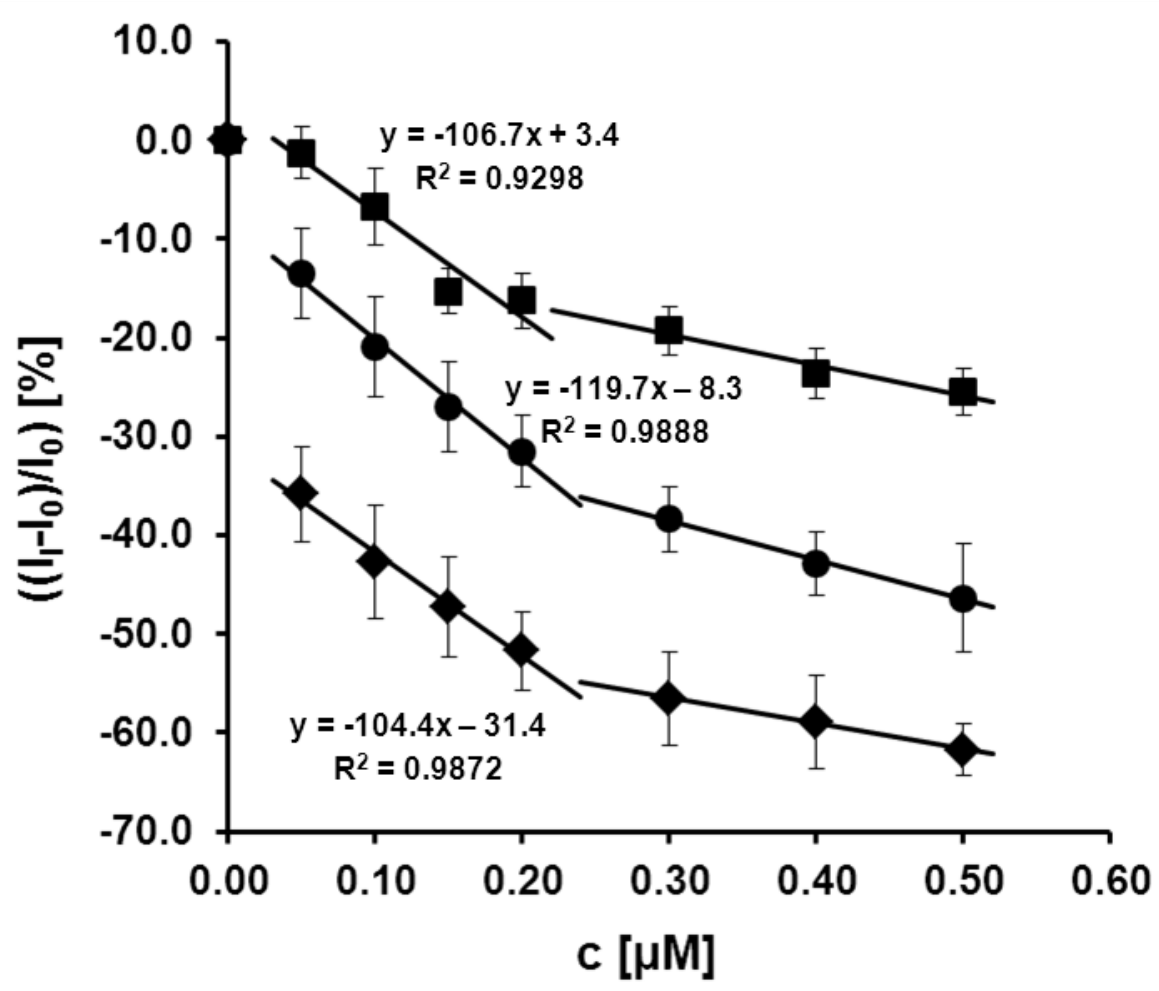

Fig. 6. Relationships between the relative intensity of $\mathrm{Cu}$ (II) redox current vs. concentration of Erlotinib (diamonds), Palmatine (circles) and Caffeic Acid (squares). 